\title{
PROMOTING WORKPLACE MEDIATION IN IRELAND: KEY RECOMMENDATIONS
}

\section{Oksana Kokaylo}

\section{Abstract}

The main focus of this article is on identifying possible ways of promoting workplace mediation in Ireland. There is a growing interest in workplace mediation but the actual level of its uptake remains very low. Workplace mediation benefits are identified and key barriers to a greater uptake are discussed. Four recommendations for Ireland have been developed based on data analysis of questionnaire responses and interviews with workplace mediation practitioners in Ireland. Practitioners' opinions and views on promoting workplace mediation in Ireland are discussed involving the role of professional bodies and individual mediators, role of the judiciary, the role of organisations. The recommendations for workplace mediation in Ireland include the involvement of the Institutional drivers, workplace mediation pilot schemes, the role of the State and the encouragement of informed decisions. The research identified that raising awareness and understanding about mediation and its benefits would be the first step to take in order to increase an uptake of workplace mediation in Ireland.

\section{Keywords}

Workplace, mediation, mediator, organisations

\section{WORKPLACE MEDIATION CONTEXT IN IRELAND}

In order to talk about the possible ways of promoting workplace mediation in Ireland it is relevant to analyse its current status of resolving workplace disputes in the Irish context.

A recent study of Alternative Dispute Resolution in Ireland undertaken by Teague et al. (2015) points out that 'firms located in Ireland are not travelling this radical innovation pathway' by 'adopting ADR practices in an integrated fashion' $(2015,294)$. The study outlines the need 'to make far-reaching innovative changes to conventional conflict management' $(2015,294)$. The Teague et al. study also indicates that 'mediation is an increasingly popular part of a systems approach to the innovative management of workplace conflict' and 'is now seen as a way of dealing with a broad range of issues' $(2015,111)$

On the other hand, the enactment of the Workplace Relations Act (2015) and the separate 
provision for mediation within Workplace Relations Commission (WRC) is a significant step forward in promoting mediation on a statutory basis (Curran et al., 2016).

There are a number of internal mediation services established in the private and public sectors in Ireland including within: Irish Rail; An Post; ESB; Dublin Port; Teagasc; and the Court Service (Teague et al, 2015, 98). Mediation is highly encouraged in the public sector in Ireland through the Civil \& Public Service Mediation Service (CPSMS) and the internal mediation scheme within the Health and Social Care Services (HSCS) (Kokaylo, 2015).

Mediation is also recommended by various 'state-sponsored' Codes of Practice in Ireland as an effective way of resolving workplace disputes. These Codes of Practice include: the Code of Practice Detailing Procedures for Addressing Bullying in the Workplace (Health and Safety Authority, 2007); the Code of Practice for Employers and Employees on the Prevention and Resolution of Bullying at Work (Health and Safety Authority, 2007); the Code of Practice on Sexual Harassment and Harassment at Work (Equality Authority, 2012); and the Code of Practice on Grievance and Disciplinary Procedures (Labour Relations Commission, 2000)(Curran et al., 2016).

In understanding the context, it is also important to be aware that the Mediators' Institute of Ireland (MII) was established in 1992 as a professional association for mediators. Currently there are more than 600 mediators registered as members of the MII (www.themii.ie).

In summary, a recent Literature Review 'Exploring the Competencies, Skills and Behaviours of Effective Workplace Mediators', conducted by the Kennedy Institute Workplace Mediation Research Group (KIWMRG), provides an effective summary of the context of workplace mediation in Ireland in the Figure 1 below (Curran et al., 2016: 7).

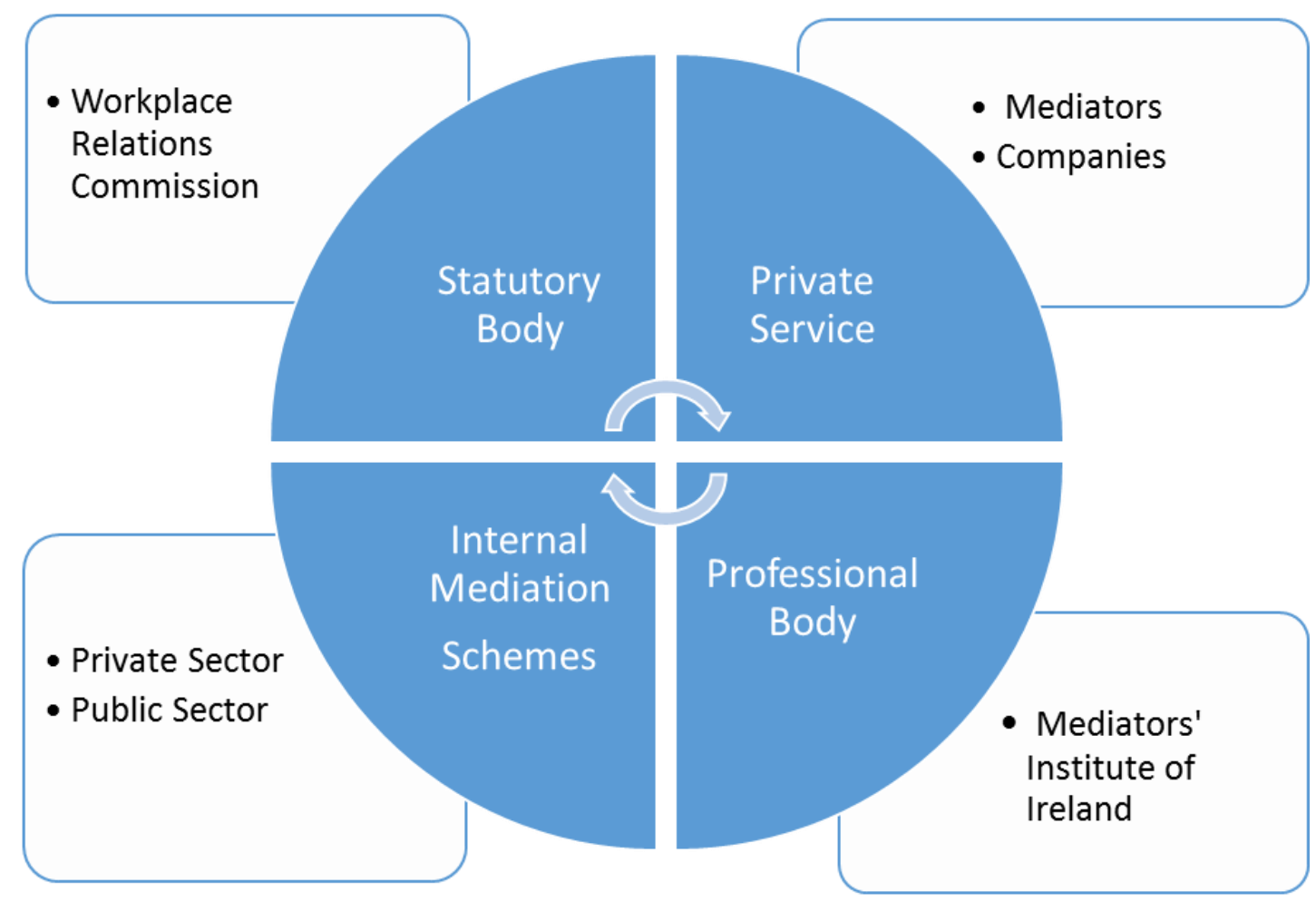




\section{Figure 1. The context of workplace mediation in Ireland (KIWMRG, 2016, 7)}

With regards to the use of mediation, Kenny provides evidence of the general increase in the use of workplace mediation in the UK 'from 42.7\% in 2008 to 57.3\% in 2011 (CIPD, 2008, 2011) with higher use among public sector employers at 82.8\%' (Kenny, 2014). However, the number of actual mediations remains very low. The overall percentage use of mediation in the private sector in the UK is just $5 \%$, falling to $4 \%$ in Small and Medium Enterprises (SMEs) "or in just 7\% of private and public sector workplaces" (Kenny, 2014). Unfortunately, there is no evidence available on workplace mediation in Ireland although this area is the subject of current Doctoral research.

The next section of this paper will focus on the main benefits of workplace mediation as an effective way of resolving workplace disputes and the reasons why it should be promoted in Ireland.

\section{WORKPLACE MEDIATION BENEFITS}

In recent research conducted by KIWMRG, (Curran et al., 2016) identify a number of benefits of workplace mediation. These include: high settlement rates combined with high levels of participant satisfaction that address substantive issues of the dispute; improved employee relationships along with restoring damaged relationships; organisational benefits including improved morale, enhanced performance, less expensive and time consuming process that can 'help to create a 'problem-solving culture' (Curran et al, 2016,11).

Despite the obvious benefits and effectiveness of workplace mediation, there are a number of barriers that might discourage organisations from using mediation for resolving workplace disputes.

The next section of this paper will explore the key barriers to a greater uptake of workplace mediation, looking at those barriers from a number of viewpoints - managerial, organisational and the challenge of getting parties to a conflict to engage in mediating resolution.

\section{KEY BARRIERS}

In exploring how best to promote greater uptake and usage of workplace mediation, it is essential to be clear in relation to what the literature has identified as key barriers and obstacles that may impede organisations from using mediation for resolving workplace disputes. The main barriers are identified below.

\section{Organisational resistance}

A lack of confidence in developing and establishing informal procedures and mediation for resolving workplace disputes can be seen among senior management and HR managers in particular. According to a recent CIPD survey report (March 2015), there are concerns among HR managers about establishing informal procedures for resolving conflicts in their organisations and instead they continue referring the cases to formal grievance procedures rather than mediation (CIPD, 2015). 


\section{Managerial resistance}

Research conducted by ACAS in 2012 indicated that the lack of "confidence and capability of line and operational managers in handling difficult issues was seen as the main barrier to early dispute resolution" (Saundry and Wibberley, 2012a) even if appropriate training and coaching were undertaken. A fear of failure as a result of uncertainty seems to lead line and operational managers to invoke the formal procedure in preference to early dispute resolution methods and mediation in particular (Saundry and Wibberley, 2012a). As a result, mediation training that might be provided to line and operational managers, does not guarantee the possibility of greater workplace mediation uptake in organisations. This lack of certainty on the part of managers seems to play a crucial role in this matter. Another obstacle that might hinder greater uptake of workplace mediation are the so-called "commercial priorities" (Saundry and Wibberly, 2012, b) of organisations. One of the surveys conducted by ACAS indicates that operational or line managers do not tend to be interested in putting maximum effort into implementing workplace mediation if there are increasing workloads and "intense pressure to improve customer service and increase efficiency” (Saundry and Wibberly, 2012b).

\section{Lack of Awareness and Understanding}

A case study undertaken by ACAS identifies a lack of awareness and understanding of mediation among staff and managers as one of the key challenges to its greater uptake. There needs to be more promotion of the concept of mediation in order to make staff aware of this option of addressing workplace disputes (Latreille, 2011). Furthermore, the ACAS case study identified a lack of understanding of how the process works and its potential benefits as an even greater barrier to its uptake. Misunderstanding of the process, as well as misunderstanding of the consequences of not engaging in it, led employees to consider mediation to be more like a punishment than a helpful tool to address workplace disputes (Latreille, 2011).

\section{Costs}

At a research seminar in 2013 in the UK, practitioners and scholars argued that costs could be a real disincentive for embedding workplace mediation in the culture of conflict management especially for small and medium sized enterprises (SMEs) (Latreille and Saundry, 2013). As a result of financial limitations, workplace mediation appears to be mostly used by large UK and US organisations, which seem to have the resources - financial, technical and human - to either provide an internal mediation service or to contract external mediators (Banks and Saundry, 2013). In June 2012, in order to support SMEs in the UK and make workplace mediation accessible, the Department for Business, Innovations and Skills launched and funded a Government-backed Regional Mediation Pilot Scheme for 24 SMEs in the Cambridge and Manchester regions (Department for Business, Innovation and Skills, 2012). 


\section{Previous negative experience of mediation}

A further challenge to a greater uptake of mediation was identified in research conducted by ACAS in 2010. This demonstrated that employer attitudes to mediation appeared to be dependent on the outcome of the most recent mediation case. Using Feuille and Kolb's concept of 'fragility', Latreille explores the influence of the mediation outcome on the perception of the value of mediation in general (Latreille, 2010a). According to the survey results, negative recent mediation experiences appear to have an impact on the future mediation adopters, leading them to possibly reject or discount using mediation for a future dispute. On the other hand, a positive attitude towards mediation also seems to be directly related to a positive outcome from the latest mediation (Latreille, 2010 b).

\section{Difficulty in quantifying mediation benefits}

Difficulty in quantifying wider organisational benefits of mediation was identified as one of the key barriers and challenges to the promotion of workplace mediation. According to Saundry, it was difficult to "sell the business case" to senior managers. This is evidenced by the fact that apart from the positive impact of mediation schemes on the organisation, senior managers wanted to understand the broader impact of mediation on the organization (ESRC Seminar Series 2012- 2013).

To sum up, there are a number of key barriers and challenges to the promotion and greater uptake of workplace mediation: managerial resistance which appears to be around the fear of "losing face" in front of employees and a perceived "threat to managerial authority"; "commercial priorities" of organisations; a lack of awareness and understanding of the mediation process; costs as a disincentive for embedding workplace mediation especially for small and medium sized enterprises (SMEs); difficulty in quantifying wider organisational benefits of mediation and the lack of continuing robust evaluation.

\section{PRACTITIONERS' PERSPECTIVE}

To identify possible ways of promoting workplace mediation in Ireland and the key barriers to its greater uptake, in summer 2015 interviews were conducted with workplace mediation practitioners in Ireland and an online anonymous questionnaire was sent to all registered members of the Mediators' Institute of Ireland. All 26 responses (6 interviews and 20 completed questionnaires) were grouped into common themes. Having analysed data from the questionnaire and interviews this section presents practitioners' opinions and views on promoting workplace mediation in Ireland.

\section{The Role of Professional Bodies and Individual Mediators}

The findings from interviews with practitioners emphasise the key role that individual mediators and professional organisations such as the Mediators' Institute of Ireland (MII) and the Chartered Institute of Personnel and Development (CIPD) could play in promoting workplace mediation in Ireland. In particular, this could take the form of advertising campaigns and the delivery of information sessions about mediation to Irish organisations with a view to educating employers, HR managers, line managers 
and employees about mediation.

The concept of 'fragility' around mediation outcomes suggests a need for appropriate education and training efforts to be delivered in organisations in order to ensure that there is a clear understanding of the process among potential parties to workplace disputes. According to the research quoted earlier, negative recent mediation experiences appear to have an impact on the future mediation adopters (Latreille, 2010a). As a result, it is important to ensure a high standard of training for mediators and an understanding by organisations (senior managers, line managers, staff and employee representatives) that mediation is not a 'magic bullet' (Latreille, 2010a). This could help to build understanding that resolution may not be reached through mediation in all cases and, even where it is not, there may still be benefits for parties such as increased clarity and understanding of the key issues.

\section{Role of the Judiciary}

Practitioners on the ground believe that the judiciary in the High Court could have a role in promoting workplace mediation by making statements about whether mediation has been used or not and, if not, encouraging its use in the future. In addition, the Labour Court could encourage the use of mediation by putting pressure on organisations to seek mediation and it could also incorporate mediation into its own work.

\section{The role of Organisations}

Practitioners in Ireland also suggest a role for trade unions and employer organisations in the promotion of mediation. Mediators are of the opinion that Irish organisations are in need of training and education programmes in mediation and conflict resolution skills at managerial level. They also identify a need for mandatory information sessions about mediation provided by qualified and accredited mediators. It is suggested that mediation should be written into organisational policies and procedures with an emphasis on the importance of more comprehensive information about mediation being included. Such steps are recognised as important measures to overcome managerial resistance to mediation within organisations and raise awareness about mediation and its benefits.

In conclusion, practitioners' views in Ireland are compatible with the literature review analysis in relation to practices of promoting workplace mediation in different jurisdictions. However, the emphasis and responsibility is placed on the professional bodies (MII, CIPD) and individual mediators. Their main role is identified as delivering information about mediation and its benefits to Irish organisations in order to increase awareness and understanding about the process of mediation. These steps are also essential to overcoming the key barriers to a greater uptake of workplace mediation in Ireland. The next section of this article presents recommendations for the Irish Government, professional mediation bodies and Irish organisations in promoting workplace mediation. 


\section{RECOMMENDATIONS FOR WORKPLACE MEDIATION IN IRELAND}

The main purpose of this section is to present four recommendations for professional mediation bodies, the Government and Irish organisations in relation to how they can contribute to promoting and, raising awareness and understanding about workplace mediation in Ireland.

\section{Institutional Drivers}

The Mediators' Institute of Ireland should become a central platform for creating and delivering structured information sessions about mediation throughout Irish organisations in order to raise awareness and understanding about mediation amongst senior management. In addition, the MII and CIPD could identify together the main HR courses in Ireland support them and deliver structured information sessions about mediation as part of all those courses.

\section{Workplace Mediation Pilot Schemes}

The Irish Government should consider the establishment of Mediation Pilot Schemes as one possible way of promoting workplace mediation in Ireland. Apart from increasing the workplace mediation uptake such pilot schemes might contribute to the raising of awareness about workplace mediation and an opportunity to spread the practice across the country. However, adequate evaluation and feedback on the outcomes and success of pilot projects is essential in terms of providing concrete evidence and data to build confidence and credibility in mediation as an effective tool for dealing with and resolving workplace disputes.

\section{The Role of the State}

The Government along with professional bodies should be actively involved in conducting empirical research regarding workplace mediation in Ireland. The government could fund research projects conducted by mediation practitioners. It is important to note that Kennedy Institute Workplace Mediation Research Group (KIWMRG) was established in January 2015 and unites practitioners and academics around the country. The KIWMRG has recently conducted a Literature Review 'Exploring the Competencies, Skills and Behaviours of Effective Workplace Mediators' (Curran et al, 2016), commissioned and sponsored by the Mediators' Institute of Ireland (MII). The Group is based in Maynooth University, Ireland and is committed to raising awareness of workplace mediation in Ireland. More information on the work of the Research Group can be found on their web site (www.kiwmrg.ie). It is recommended that such research projects could be sponsored and encouraged by the Irish Government as one of the ways of promoting workplace mediation in Ireland.

\section{Encouraqing Informed Decisions}

In the Irish organisational context mediation should be written into organisational policies and procedures and consideration given to mandating mediation information sessions for parties in a dispute 
before they can proceed to formal, more adversarial dispute resolution options. Another step that could be taken within Irish organisations is training and education at a managerial level about mediation and conflict resolution skills.

Establishment of mandatory information sessions about mediation within organisations provided by qualified and accredited mediators would also be an important step in increasing workplace mediation uptake in Ireland. One of the suggested approaches would be the inclusion of mandatory information sessions about mediation into future revisions of the Workplace Relations Act (2015).

\section{Conclusion}

The main purpose of this article was to present basic recommendations for wider promotion and use of mediation in the workplace in Ireland. Pursuing this goal, the author explored the views and the opinion of mediation practitioners on the ground in Ireland. Critical analysis of the data enabled the author to make recommendations in relation to the promotion of workplace mediation in Ireland. The findings indicate that professional mediation bodies such as the Mediators' Institute of Ireland and individual mediators would have an essential role in promoting workplace mediation in Ireland. It was also highlighted that the Government would have a key role in promoting workplace mediation in Ireland by establishing and funding mediation pilot projects and sponsoring research projects conducted by the KIWMRG. The lack of awareness and understanding about the mediation process and its benefits was identified as one of the key barriers to a greater uptake of workplace mediation, and in the Irish context in particular. Professional mediation bodies in conjunction with the Government would play a critical role in overcoming the key barriers to a greater uptake of workplace mediation in Ireland.

"It is important to encourage, support and promote workplace mediation in Ireland at every level including the State, the Judiciary, professional bodies, private and public organisations, individual mediators"

(The quote is taken from Interview 2). 


\section{References}

Banks, L. and Saundry, R. (2013) 'Mediation - a panacea for the ills of workplace dispute? A comprehensive review of the literature examining workplace mediation', iROWE Research paper No. 1, p.16 www.uclan.ac.uk [accessed 2.02.16].

Chartered Institute of Personnel and Development (2015) 'Conflict management: a shift in direction?' CIPD Survey Report, p.3.

Curran, D., Kenny, T., Bouchier, M., Meehan, L., Dillon, J., Kokaylo, O., Joyce, C., Coakley, A., Barry, B., Murray, G. (2016) 'Exploring the Competencies, Skills and Behaviours of Effective Workplace Mediators', Literature Review conducted by Kennedy Institute Workplace Mediation Research Group (KIWMRG).

Department for Business, Innovation and Skills (2012) 'Regional mediation pilot scheme launched' $<$ https://www.gov.uk/government/news/regional-mediation-pilot-scheme- launched $>$ [accessed $5 / 03 / 16]$.

ESRC Seminar Series 2012-2013 'Reframing Resolution - Managing Individual Workplace Conflict' Seminar 3, 'Mediation and alternative dispute resolution - outcomes and impacts'http://mrclabsestream.swan.ak.uk/Embed.aspx?id=2410\&wmode=opaque

$\&$ code $=$ ah $\sim$ RGBSHaehlNmB96RxQECQyW [accessed 18/02/16]

Kenny, T. (2014). 'Developing the Conversation about Workplace Mediation', The Journal of Mediation and Applied Conflict Analysis, Vol 1(1).

Kokaylo, O. (2015) 'Possible Ways to Promote Workplace Mediation in Ireland and Key Barriers to a Greater and More Effective Use of Mediation' (unpublished) A dissertation submitted in a partial fulfilment of the requirements of the Higher Education Training \& Awards Council for the degree of MA in Dispute Resolution, Independent College Dublin.

Latreille, P.L. (2010a) 'Mediation: A Thematic Review of the ACAS-CIPD Evidence' ACAS Research Paper,13/11, p.56.

Latreille, P.L. (2010b) 'Mediation at work: success, failure and fragility', ACAS Research Paper, p.2, 20.

Latreille, P.L. and Saundry R. (2013) 'Review of Seminar 3 - Mediation and alternative dispute resolution - outcomes and impacts', p.4.

Saundry, R. and Wibberley, G. (2012) 'Mediation and Early Resolution: A Case Study in Conflict Management', ACAS Research Paper, 12/12,p.20-22.

Teague, P., Roche W., Gormley, T., and Currie D. (2015) 'Managing Workplace Conflict: Alternative Dispute Resolution in Ireland'. IPA, Ireland. 
Oksana Kokaylo is a member of the Kennedy Institute Workplace Mediation Research Group (KIWMRG). She is among ten volunteers who participated in the research project Exploring the Competencies, Skills and Behaviours of Effective Workplace Mediators' conducted by the KIWMRG and coordinated by Deirdre Curran. Oksana has a MA in Dispute Resolution from Independent College in Dublin. She is a certified member of the Mediators' Institute of Ireland and a member of the MII Workplace Mediation Group. Oksana can be contacted at oksanakokaylo@gmail.com.

\section{Acknowledgments}

The author would like to acknowledge Kennedy Institute Workplace Mediation Research Group (KIWMRG) Writing Circle for their support, encouragement and very helpful comments on draft of this article. A special word of thanks to Deirdre Curran, Treasa Kenny, Margaret Bouchier and Mary Rafferty for their guidance and inspiration. A big thank you to the case study interviewees and questionnaire respondents, who have given up their time to assist in my research. 